\title{
Realidad aumentada e innovación tecnológica en prensa. La experiencia de ver y escuchar un periódico impreso
}

\author{
María Dolores Meneses FernándeZ \\ Universidad de La Laguna \\ dmeneses@ull.es \\ Jorge MARTín GUTIÉRREZ \\ Universidad de La Laguna \\ jmargu@ull.es
}

Recibido: 16/09/2011

Aceptado: 25/02/2012

\begin{abstract}
Resumen
Los autores analizan el sistema de visualización de contenidos mixtos denominado realidad aumentada y su aplicación en medios impresos. En este artículo se revisa su uso en la prensa a través de ejemplos de diarios y revistas españolas y extranjeras impresas, que han incorporado a su oferta contenidos aumentados. Mediante una demostración y un sondeo se testan la viabilidad y los efectos de esta tecnología, con el fin de evaluar qué supone su inclusión en un periódico.

Palabras clave: Tecnología periodística, innovación periodística, realidad aumentada, realidad mixta, periodismo.

\section{Augmented Reality and Technological Innovation in Press. The Experience of Watching and Listening to a Printed Newspaper}

\begin{abstract}
This paper analyzes the technological base of Augmented Reality, a display system whose application in the media is currently increasing. The aim is to explore the possibilities and effects in print newspapers. The authors are focuses on Spanish and foreign newspapers and magazines which are incorporating this option in their issues. A survey and a questionnaire were designed to know what means the application of Augmented Reality in print media for professionals and consumers.

Keywords: Newspaper technology, Journalistic innovation, augmented reality, mixed reality, journalism.

\section{Referencia normalizada}

MENESES FERNÁNDEZ, María Dolores y MARTÍN GUTIÉRREZ, Jorge (2013): "Realidad aumentada e innovación tecnológica en prensa. La experiencia de ver y escuchar un periódico impreso". Estudios sobre el mensaje periodístico. Vol. 19, Núm. 1, págs.: 207-221. Madrid, Servicio de Publicaciones de la Universidad Complutense.
\end{abstract}

Sumario: 1. Introducción. 2. Contextualización y consistencia de la RA aplicada al periodismo. 3. Objetivos y metodología. 4. Revisión de casos. 5. Sondeo a usuarios. 6. Infraestructura y coste económico. 7. Resultados. 8. Conclusiones. 9. Referencias bibliográficas.

\section{Introducción}

En el número de diciembre de 2009 la revista impresa Esquire, editada en EE.UU., incluía una serie de contenidos denominados aumentados. Para atraer la atención de su público, hombres de un nivel socioeducativo y económico medio, medio-alto, la redacción estampaba en la portada una figura geométrica en blanco y negro, situándola 
entre las piernas del personaje de la fotografía de apertura. Era imposible que pasara desapercibida, puesto que la innovadora oferta merecía un despliegue visual acorde con la primicia. El editor de Esquire, David Granger, presentaba en la web de la revista un vídeo en el que explica la novedad y la consistencia de algo aludido bajo las siglas AR.

Quizá éste no sea el primer caso de aplicación periodística del sistema de visualización de contenidos mixtos denominado Realidad Aumentara (RA, de la expresión inglesa Augmented Reality, AR), pero los expertos coinciden en considerarlo uno de los detonantes. Es un ejemplo que muestra cómo las tecnologías de la información y la comunicación (TIC) calan en el sector de la prensa, creando originalidad. La situación económica de la industria editora de medios impresos incita a los diarios y revistas a agudizar el ingenio para sobrevivir ante a la competencia.

El periodismo impreso -como la publicidad- está concernido por las posibilidades que dan los nuevos dispositivos y plataformas (ordenadores, teléfonos inteligentes, tablets, videoconsolas) con conexión a Internet. En este estado de cosas, el éxito de la asociación de prensa, dispositivos con webcams, pantalla y conexión a la Red dependerá del aporte que haga en la tarea informativa, de la accesibilidad y usabilidad para los lectores. Si hay éxito las TIC contribuyen a la supervivencia del periodismo impreso, precisamente en medio de tantas TIC competidoras.

En este artículo exponemos el funcionamiento de la RA y revisamos varios de los casos más conocidos de su aplicación en periódicos. Son cabeceras de distintos países que consideran esta tecnología una forma de ganar en competitividad, de ofrecer contenidos de forma original y de diferenciarse de sus iguales.

\section{Contextualización y consistencia de la RA aplicada al periodismo}

El periodismo se ha visto históricamente impulsado, y en ocasiones sacudido, por los avances que la innovación tecnológica pone al alcance de las empresas editoras. La tecnología jalona la evolución de la prensa, modificando las fases y agentes del proceso comunicativo: desde la captura de recursos hasta el consumo de los contenidos. Cada vez más autores reflexionan sobre cómo influyen las TIC en el procedimiento periodístico, en el modelo de negocio, en su esencia y enseñanza (Casals, 2006: 61; Salaverría y García, 2008: 35).

Centrándonos en la tecnología que nos ocupa, si bien una de las primeras aplicaciones periodísticas con impacto es la de Esquire, los ensayos pioneros de esta tecnología datan de finales de los años sesenta y principio de los setenta del siglo XX. Los que motivó posibilitar un tipo de visión que permitiera superponer, en la pantalla de un dispositivo, datos, información, imágenes fijas o en movimiento, animación y locuciones, a lo observado a simple vista (o visión primaria). La complementariedad de los contenidos de un escenario real (la plana de un periódico, por ejemplo) y otro virtual es lo que diferencia la RA de la realidad virtual, por lo que no hay que confundirlas.

Unos autores definen la RA como una tecnología capaz de generar una realidad mixta por ordenador (Bloem y Aart, 2010: 5); otros la consideran una nueva forma de visión consistente en generar una realidad complementada (Feiner, 2002: 14). En cual- 
quier caso, lo que el receptor percibe son contenidos mixtos: la realidad más lo aumentado superpuesto. Con esta idea, en 1999, el Centro de Nuevos Medios de la Escuela de Periodismo de la Universidad de Columbia (Nueva York) construyó un prototipo de lo que denominó Estación Móvil de Trabajo para Periodistas (Mobile Journalist's Workstation). Era un pesado y caro dispositivo portátil que permitía al periodista visualizar presentaciones hipermedia 3D superpuestas a lo que se estuviese percibiendo en la realidad, tanto en lugares al aire libre como en espacios interiores. Además, podían estar localizados por GPS y enviar datos por módem a la redacción (Höllerer, Feiner y Pavlik, 1999a: 79-86; Höllerer, Feiner y Pavlik, 1999b; Pavlik, 2002: 11; Lapointe, 2002: 144). En 2011, doce años después, nos encontramos con una aplicación evolucionada que permite, entre otras cosas, leer el periódico en papel de una forma antes no imaginada, tal y como muestra P. Maes y P. Mistry (2009, vídeo TED, 6' 34"), y M. Bunz (2010a).

De aquella investigación pionera de 1999 también derivó la posibilidad de localizar los hechos noticiosos en el lugar en el que acontecen, fundamento del periodismo, pero pudiéndolos visualizar ahora a partir de una plana de papel, no de la televisión. Aquí, la RA sitúa al lector en el lugar de la noticia, superponiendo capas de información multimedia al texto impreso, descodificándolas con una webcam o unas gafas (Höllerer y otros, 1999a: 79; Bradshaw, 2010: 1). Así, en el caso de contenidos aumentados referidos a lugares reales, surge la sensación de telepresencia, de estar en el lugar de los acontecimientos, otra interfaz en auge (Puro, 2011: 128).

Es, por tanto, una tecnología que permite un tipo de visión mixta, híbrida o mezclada, directa o indirecta, de contenidos superpuestos a la realidad física. Da la posibilidad de añadir algo sobre lo que percibimos a simple vista, esto es, aumentar la visión normal de la realidad. Es por ello que se la denominada Realidad Aumentada (RA, de la traducción de su denominación en inglés Augmented Reality o AR) (Lapointe, 2002: 144).

El aporte de RA radica en las posibilidades de la informática, las 3D y la tecnología web. Su uso en medios impresos posibilita combinar la realidad física y la virtual; la realidad física es el papel y la virtual son los contenidos aumentados desplegados en la pantalla de un dispositivo con cuya cámara enfocamos la plana. A su explotación en periodismo se suma el cómic, los libros, los museos, el cine, la publicidad, el marketing en línea, el street marketing o marketing callejero, la venta por catálogo, el detal, diversos productos editoriales, la telefonía móvil, la geolocalización y los eventos como ferias, congresos, convenciones, entre otras posibilidades.

Es una tecnología que mejora la experiencia receptora en periodismo impreso y diversifica el canal de comunicación, ya que genera por ordenador imágenes en 3D y omnidireccionales, que complementa la mancha de la página. Los lectores cuentan así con información virtual superpuesta a la impresa sobre la que se despliegan los contenidos aumentados; basta con enfocar la página con la cámara del dispositivo y visualizarlos en el display.

Como dice M. Bunz (2010b), el periodismo y la Realidad Aumentada están hechos el uno para el otro, volviendo vivientes las revistas y los diarios en papel. Es por ello que, en países como EE.UU., los productores del sector periodístico confirman 
que las redacciones de los medios están incorporando la RA con grandes expectativas (Thornton, 2010: 1; Fundación Telefónica, 2011: 16-21). Estamos ante un tipo de tecnología expansiva que complementa algo preexistente; es la vía para ver en una página de papel más de lo que está impreso a simple vista. Tal y como avanzaba J. V. Pavlik hace una década, la RA comienza a introducirse en el periodismo, aunque a un ritmo lento (Pavlik, 2001, pp. 3, 20, 54, 59 y 85).

La representación gráfica en una Hype Cycle de Gatner permite observar, en el eje temporal, la madurez en la adopción de las tecnologías emergentes, desde su fase incipiente hasta la normalización, decepción del uso o sustitución por otras tecnologías, pasando por el periodo de consumo eufórico. La posición actual de la RA en la Hype Cycle está en el tramo de ascenso casi en la cima de la primera parábola; lo ejemplifica su uso en la publicidad y en los contenidos de ficción (Fundación Telefónica, 2011: 37; Madinaveitia, 2011: 79-81); sin embargo, si nos ciñésemos a su aplicación en el periodismo descenderíamos a la fase incipiente (Fenn, 2010: 1-20). La aplicación de la RA en periodismo impreso supone una manera nueva de presentar los contenidos; de hecho, los autores citados hablan de información inteligente por poseer el marchamo de real y por facilitársela al destinatario en toda su dimensión, superando las limitaciones del papel.

Estamos en una de esas situaciones en las que una tecnología de visualización permite canalizar datos e información antes recibida, de forma limitada, por un sólo medio de comunicación: el periódico. El reto es que esta forma de difundir contenidos sea más potente que la anterior.

\section{Objetivos y metodología}

El objetivo principal de este artículo es ofrecer el estado del arte de la RA en el periodismo impreso. Para ello revisamos la aplicación de este sistema de visualización en varias cabeceras españolas y extranjeras. El objetivo secundario es describir cómo funciona la RA, teniendo en cuenta los elementos del proceso periodístico. En tercer lugar se proporcionan datos para conocer la viabilidad económica de esta tecnología en una empresa periodística.

Tecnologías como la RA y las 3D aportan alicientes entre los consumidores de medios impresos. El requisito es, junto con disponer del ejemplar en papel, estar predispuesto a mezclar los contenidos leídos con otros audiovisuales, valiéndose de un ordenador o de un smartphone. La condición de adquirir el ejemplar para disfrutar del material aumentado no es una cuestión trivial, considerada la situación del sector prensa.

Si nos circunscribimos a España, la RA es casi desconocida en el ámbito de la prensa, más aún en la local; por tanto es interesante conocer la opinión de los usuarios de una tecnología integrante de la denominada innovación abierta (Arroyo-Vázquez y Guallar, 2010: 107; Alcántara et al., 2009: 1-31).

Para cubrir esos objetivos, planificamos el trabajo en tres fases:

- La primera consistió en la revisión de prensa española y extranjera con contenidos aumentados, procurando compilar los argumentos de los responsables de las cabeceras con los que justifica tal innovación en sus páginas. 
- En la segunda fase realizamos una demostración de contenidos aumentados, en vídeo y $3 \mathrm{D}$, a un grupo de 46 alumnos de $3^{\circ}$ de Grado en Periodismo de la Universidad de La Laguna, varios de ellos con experiencia profesional en medios. Luego se les hizo un sondeo para valorar los aspectos de esta tecnología, registrando las respuestas en una plantilla. Para la demostración citada los autores aumentaron varias piezas de periódicos diarios impresos.

- La tercera fase se centró en estimar la inversión que implica incorporar la RA a un periódico. Para ello se consultaron los precios de los softwares visualizadores para ordenador y smartphone.

\section{Revisión de casos}

Son varios los ejemplos de utilización de la RA en revistas españolas y extranjeras. Son las que están actuando de escaparate de esta tecnología, despertando el interés de estudiosos y profesionales. Nos centramos en las cabeceras siguientes:

- Esquire (EE.UU.), revista mensual dirigida a hombres de un nivel socioeducativo y económico medio, medio-alto. El editor de esta revista mensual en papel, David Granger, presentó un vídeo en Internet para presentar el número de diciembre de 2009 en el que incluían RA ${ }^{1}$, (figuras 1 y 3 ). Los contenidos aumentados incluyen una exhibición de los personajes incluidos en el número hasta unas declaraciones de otros.

- Guardian.co.uk (Reino Unido). Diario inglés dirigido a un público de ideología progresista, clase media burguesa integrada por profesionales liberales. Entre diciembre de 2009 y enero de 2010 la versión digital de este diario de información general publicó varios post sobre la aplicación de la RA en periodismo, incluida un vídeo con ejemplos de geolocalización ${ }^{2}$.

- Wallpaper (Reino Unido) es una revista mensual de diseño, moda, viajes y tecnología dirigida a lectores jóvenes de clase media atraídos por un periodismo visual con temática variada, actual y centrada en tendencias de consumo. Comenzó a ofrecer contenidos aumentados en el número de enero de 2010 (figura 1). Quizá sea la publicación que de forma más prolongada utiliza la realidad mixta. La importancia que le concede esta publicación queda manifiesta en el proyecto que dedican a esta tecnología, según exponen en http://www.wallpaper.com/ar y http://media.wallpaper .com/pdf/WallpaperJan2010.pdf. Los contenidos aumentados van en consonancia con la temática de la cabecera: sesión de fotografías de moda, diseño, tendencias, estilos de vida, interiorismo y arte.

- Grazia (Italia) es un magacín semanal italiano dedicado a la moda y dirigido a mujeres jóvenes de clase media interesadas por tendencias de consumo. La edición británica en papel introdujo en el número del 23 de marzo de 2010 contenidos 3D y RA que califican de increíbles y primicia emocionante; el objetivo manifestado por su

1 Consultable en la web de la revista http://www.esquire.com/cover-detail?year=2009\&month $=12$ y en su canal en YouTube: http://www.youtube.com/user/EsquireMag\#p/search/3 /LGwHQwgBzSI

2 En http://www.guardian.co.uk/travel/video/2009/dec/10/augmented-reality-travel-apps?INT $\mathrm{CMP}=\mathrm{SRCH}$ 
editora jefe, Jane Bruton, es divertir y asombrar a sus lectores con exhibición de moda, declaraciones y reportajes ${ }^{3}$. Esta revista ha vuelto a utilizar este sistema de visualización en números posteriores.

- SZ Magazin del (Alemania) es el suplemento semanal en papel del diario muniqués Süddeutsche Zeitung). Su público son lectores de clase media e ideología de centro y progresista interesados en temas sobre estilos de vida. Dedica en la versión digital varios post a la RA, uno de ellos centrado en explicar cómo disfrutar de los contenidos aumentados del número 33 del 20 de agosto de 2010 (figuras 1 y 3), que van desde un reportaje fotográfico y simulaciones hasta las respuestas del crucigrama. Utilizan un smartphone y la aplicación es Junaio ${ }^{4}$.

- Fotogramas (España) es una revista mensual de cine destinada a un público variado interesado en esa temática. El número de septiembre de 2010 incluye una entrevista de la que Pere Vall, redactor jefe, expone la consistencia en el video alojado en http://www.fotogramas.es/Noticias/Prueba-la-Realidad-Aumentada-de-FOTOGRAMAS (figuras 1 y 3). En este número explotan de forma espectacular la RA en una entrevista al personaje de portada, en la sección crítica cinematográfica y en varios videoclips. De esta forma, la información se ofrece bien combinada con entretenimiento y humor.
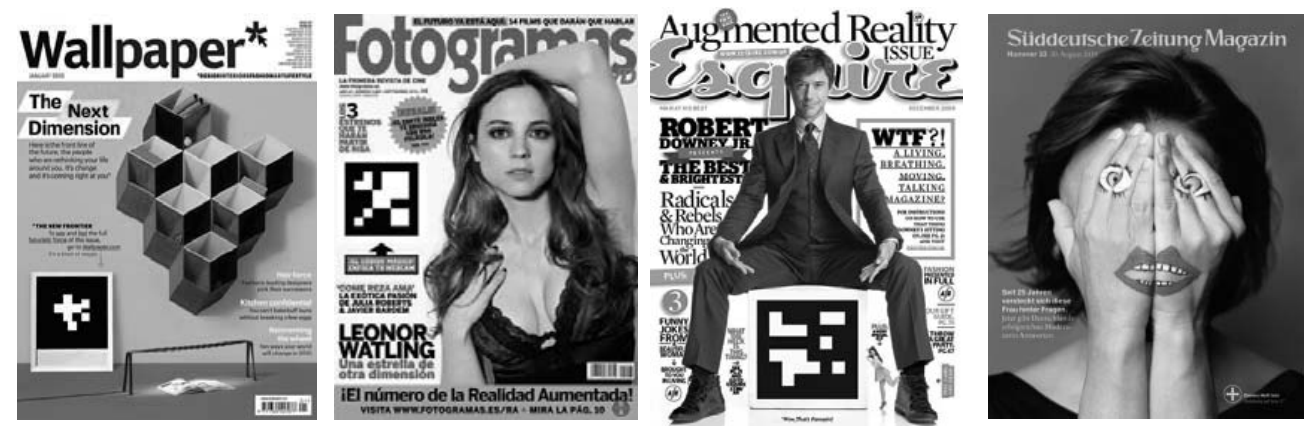

Figura 1. Portadas de las revistas Wallpaper (Gran Bretaña) Fotogramas (España), Esquire (EEUU) y SZ Magazin (Alemania) con los marcadores que actúan como patrones de reconocimiento cuando son enfocados con la webcam y descifrados por el software de RA instalado en el dispositivo.

Estas experiencias pioneras datan de entre finales de 2009 y mediados de 2010. Los perfiles de los lectores y la periodicidad semanal o mensual de las cabeceras coinciden. La RA se aplica en estos números para aumentar contenidos variados, con el componente del entretenimiento como denominador común. Los editores comparten una actitud optimista al anunciar los números aumentados, presentan sus propuestas respectivas como una primicia e invitan a los lectores a disfrutar y divertirse con ellas.

${ }^{3}$ El vídeo de presentación del número está en http://www.graziadaily.co.uk/video/archive /2010/03/23/video — check-out-grazia-s-3d-walk-in-talking-issue.htm y en http://www.graziadaily.co.uk/video/archive/2010/03/23/watch-grazia-s-pages-come-to-life.htm

${ }^{4}$ La versión en alemán del vídeo puede consultarse en http://sz-magazin.sueddeutsche.de /texte/anzeigen/34537 y la inglesa en http://www.youtube.com/watch? $\mathrm{v}=\mathrm{LRceOYbrVzc}$. 
Observamos que la RA es una tecnología que permite la narrativa no lineal y en capas, pudiéndose abordar tramas informativas que desbordan los límites de la plana (Lindstedt et al., 2009: 3-20). Facilita incluir distintos niveles de lectura y atrae a lectores con intereses y expectativas dispares. Sin embargo, dar coherencia a una pieza periodística que no se desarrolla sólo en los límites de la página de papel, y que pasa a mezclar recursos textuales y audiovisuales, requiere guionizar los contenidos en un medio poco habituado a ello como es la prensa. Un ejemplo es el situated documentary (Höllerer, Feiner y Pavlik, 1999b: 1), un género surgido de la RA caracterizado por "A situated documentary enables news consumers to visit the site of past news events and thereby be immersed in narrated multimedia presentations about those past events. [...]. Together, these technologies can help provide vital information to citizens to help the them make better-informed decisions." ${ }^{\text {. }}$. El autor de la pieza periodística deberá ordenar, articular y cohesionar recursos diversos para que el lector los reciba y descodifique de forma óptima.

\section{Sondeo a usuarios}

El sondeo se realizó a un grupo de 46 estudiantes de $3^{\circ}$ de Grado en Periodismo. Las respuestas fueron abiertas centradas en cuatro relaciones: a) RA y trabajo periodístico; b) RA y formación del periodista; c) RA y usuario final, y d) RA y empresa editora.

Ordenamos las respuestas en dos apartados: profesional y receptor, y cada uno de ellos en dos subapartados: pros y contras de la RA. Registramos el número de veces que se repetía cada respuesta.

Las respuestas obtenidas pueden sintetizarse en los cuatro aspectos siguientes:

1. Infraestructura: características del sistema de visualización y su tecnología.

2. Costes del sistema: para empresa (inversión), el periodista (formación) y el destinatario (gasto en dispositivos).

3. Contenidos: cantidad y calidad de los contenidos periodísticos aumentados.

4. Proceso: usabilidad del sistema para acceder a los contenidos aumentados.

Coincidiendo con lo que afirma D. Mensing (2010: 11), los estudiantes encuestados manifestaron que informar usando la RA exige inversión a las empresas y formación a los periodistas, y que mejora el producto informativo porque no sólo incorpora veracidad, también atractivo.

\section{Infraestructura y coste económico}

Otro objetivo de este trabajo es estimar los costes del uso de la RA. Se corresponde, precisamente, con una de las respuestas más repetidas $(19+17=36)$ en ambas columnas de los contras. Hemos descrito este sistema de visualización en lo que respecta a su aprovechamiento en periodismo, pero para cuantificar el gasto aproximado que su-

5 PAVLIK, John V., 2002, p. 11: "Un documental situado permite a los consumidores de noticias visitar el sitio en el que han ocurrido los acontecimientos noticiosos y, por lo tanto, estar inmersos en los acontecimientos gracias a ser narrados mediante presentaciones multimedia. [...] En conjunto, estas tecnologías pueden ayudar a proporcionar información vital a los ciudadanos para la toma de decisiones mejor documentadas". 
pone incorporarlo hay que tener en cuenta su base técnica, la infraestructura y los profesionales necesarios.

Desde el punto de vista técnico, la definición propuesta por P. Milgran (1994: 13211329) para el término realidad aumentada es la más referenciada y aceptada. En función de la cantidad de objetos virtuales añadidos a la escena real, gestionada por el ordenador, propone la clasificación mostrada en la figura 2.

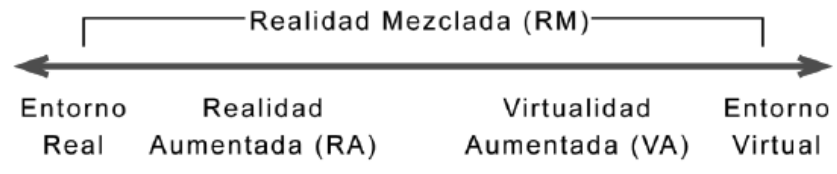

Continuo de Virtualidad
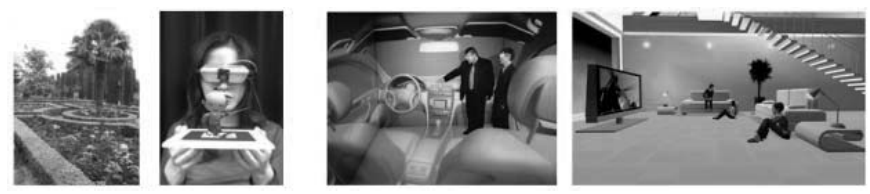

Figura 2. Representación de Milgram y Kishino del virtuality continuum (1994: 1321-1329), donde RA es parte de RM. Adaptado por Azuma y colaboradores (2001: 34-47).

Por su parte, R. Azuma define la RA como los sistemas que reúnen simultáneamente tres características: mezcla de lo real y lo virtual, interactividad en tiempo real y registro tridimensional. La definición de R. Azuma, junto con el continuo de P. Milgram, es la comúnmente aceptada:

Realidad aumentada es una variación de los entornos virtuales. Las tecnologías de realidad virtual sumergen completamente a un usuario dentro de un entorno sintético. Mientras se está inmerso, el usuario no puede ver el mundo real a su alrededor. En contraste, la realidad aumentada permite al usuario ver el mundo real con objetos virtuales, superpuestos o mezclados con el mundo real. Por lo tanto, la realidad aumentada no sustituye el entorno real (Azuma, 1997: 355-385).

La introducción de elementos virtuales en la escena real puede hacerse mediante marcadores, códigos o etiquetas (figuras geométricas blancas y negras), imágenes, fotografías, geolocalización e incluso por reconocimientos faciales y gestos. Para visualizar la información virtual en la escena real, el usuario debe disponer de un dispositivo con pantalla gráfica, provisto de una cámara web común: ordenador personal, smartphone, videoconsolas o gafas virtuales. Como vemos, algunos de esos dispositivos son de uso común, pero otros (las gafas) aún no están extendidos.

Además de los dispositivos anteriores se precisan softwares: los específicos para enlazar y visualizar los contenidos aumentados, y los utilizados para el modelado en $3 \mathrm{D}$. Estos segundos son usados habitualmente por los diseñadores. Respecto a los primeros, cabe la posibilidad de crear aplicaciones RA para ordenadores personales y smartphones, o, la opción óptima, alojarlas en una web -la del periódico, por ejemplo; en este caso el lector puede descargarla en su dispositivo o ejecutar la aplicación del visor en la propia web. El mercado ofrece varios softwares comerciales y libres para ordenadores; sin embargo los de smartphones son escasos y limitados. 
Los marcadores o etiquetas apenas implican gastos, ya que se insertan fácilmente en la plana; en caso de que no sean marcadores geométricos, sino imágenes reales, puede ser la foto de las noticias. Es el software lo que permitirá vincular los marcadores a la información virtual de forma que, al ser captados por la cámara web, se mostrará en la pantalla la información virtual superpuesta a la imagen real (figuras 3a y 3 b). Otra técnica para introducir la información aumentada en el entorno real es asociarla a coordenadas geográficas, de forma que el posicionamiento de la información añadida se realiza por geolocalización, mediante señal GPS, enfocando con la cámara del dispositivo un edificio, por ejemplo; en esta modalidad el periódico impreso es prescindible.

En definitiva, el usuario sólo necesita un dispositivo con pantalla gráfica, una webcam y un software en un ordenador personal, un tablet o un smartphone con acceso a Internet. Lo utilizaría como muestran las figuras $3 a$ y $3 b$.
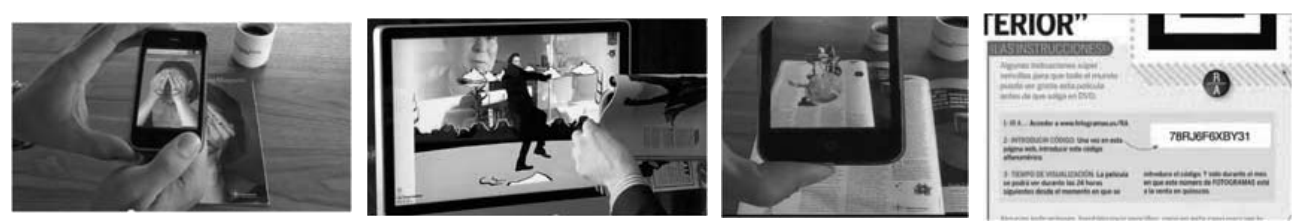

Figura 3a. Ilustración de cómo se despliega en la pantalla del dispositivo los contenidos aumentados al enfocar la fotografía enlazada al archivo escena (SZ Magazin y Esquire), e instrucciones a los lectores (Fotogramas). Fuente: web de las cabeceras.
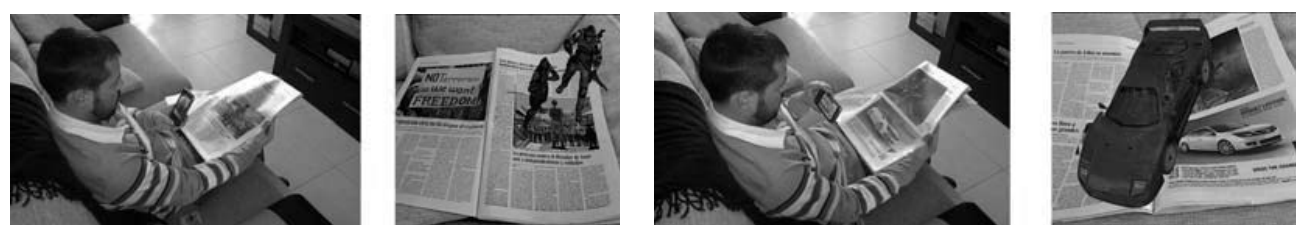

Figura 3b. Contenidos aumentados por los autores y enlazados a imágenes de un diario.

En contra de lo que puede pensarse, crear aplicaciones de RA está al alcance de todos. El software para crearlas no requiere conocimientos de programación. El diseñador, utilizando sus herramientas informáticas habituales, creará en 2D ó 3D imágenes o las capturará en vídeo/audio para complementar la pieza impresa. Con el software de RA podrá crear nuevos marcadores o usar los que tiene por defecto (librerías), aunque las últimas versiones permiten utilizar imágenes (fotos) en lugar de marcas. Como se observa, la base del software es relacionar una marca o una fotografía con un archivo de animación 3D, vídeo o audio, de manera que el redactor asigne a cada marca o imagen el contenido digital de un archivo.

El contenido digital se colocará en una posición determinada con respecto a la marca, de forma que la posición del objeto (pensemos en una infografía o un entrevistado) con respecto a la marca es única para que se despliegue con su orientación correcta. Por tanto, cada marca o imagen tiene asociado un contenido digital; el software guarda este trabajo en un archivo denominado escena; en ese momento, la aplicación de RA ha terminado. La escena (archivo) se deposita en el servidor del periódico para 
que el usuario pueda acceder, vía web, a ella. Cuando accede a la web se ejecuta de forma automática el archivo escena, apareciendo en la pantalla del ordenador o del smartphone un visualizador, es decir, la imagen que está enfocando la webcam del dispositivo. Cuando el usuario enfoca la marca o fotografía impresa en la plana, que el diseñador ha utilizado para crear la escena; entrando en el campo de visión de la webcam, se mostrará en la pantalla del dispositivo el contenido aumentado que tiene asociado. El periódico en papel es necesario porque contiene la clave para que se despliegue sobre la página los contenidos aumentados: una infografía 3D, una entrevista, un reportaje audiovisual, por ejemplo.

El geoposicionamiento sustituye la marca o la fotografía por coordenadas geográficas espaciales. La información digital sólo se podrá visualizar si el dispositivo del usuario tiene GPS para conocer en qué coordenadas está, de tal manera que al enfocar con la cámara el punto -la fachada de un edificio, por ejemplo- a cuyas coordenadas está vinculada la información aumentada, se mostrará en la pantalla la imagen real y la imagen virtual superpuesta.

La empresa periodística que quiera incorporar la RA ha de cubrir ciertos requisitos de hardware y software. En cuanto a hardware, deberá disponer de un ordenador con el que crear las aplicaciones RA, un servidor para alojar el visualizador de las escenas y las escenas, y un dispositivo de captura de imágenes (webcam) o de geoposicionamiento (smartphone), en función del tipo de aplicación por la que opte: marcadores, fotografías o geoposicionamiento.

Un componente clave del software es el reconocedor de patrones, ya que la RA se fundamenta en técnicas de visión por ordenador, es decir, el programa debe ser capaz de reconocer rápidamente y sin ambigüedades la forma del marcador o la fotografía para mostrar el elemento virtual vinculado a ella. Si el reconocedor no es estable dará la sensación de que las imágenes aumentadas vibran o saltan. El software debe disponer de librerías de reconocimiento adecuadas, con abundantes marcadores. Las últimas versiones de software han mejorado, permitiendo al diseñador crear sus propias marcas e incluso utilizar fotografías u otras imágenes. El programa debe tener también un visualizador, es decir, un subprograma para ejecutar escenas y visualizarlas. Las cabeceras revisadas aquí han utilizado marcas, como se observa en sus portadas (figura 1).

El mercado ofrece un número reducido de softwares comerciales para crear aplicaciones de RA, pero con amplias prestaciones y reconocedores de patrones estables (Metaio, Total Inmersion o Qualcomm). Los softwares libres disponibles han sido desarrollados en institutos de investigación y universidades (ARToolKit, OSGART, AMIRE, ARTag, FLARToolkit, MXRToolkit, MRToolkit y BuildAR, entre otros). Actualmente, varios centros de investigación desarrollan aplicaciones para lograr reconocedores aún más estables y potentes. Sin embargo, las aplicaciones libres sólo permiten RA en ordenadores personales, no en móviles; para éstos se debe utilizar las comerciales (smarphones: Android, IPhone).

La infraestructura requerida para ofrecer RA consta de los componentes siguientes:

- Ordenador personal con las especificaciones para trabajar con programas de diseño gráfico y provisto de cámara web.

- Smartphones. 
- Software para crear aplicaciones de RA que permitan relacionar la información virtual con marcadores/imágenes.

- Entorno web donde alojar el visualizador y las escenas aumentadas.

- Diseñador gráfico o personal cualificado capaz de crear contenidos aumentados en 2D o 3D. De hecho, la creación de los contenidos es el trabajo más laborioso del proceso y dependerá de la habilidad del diseñador.

Esta configuración es la adecuada para periódicos, ya que no precisa que los lectores instalen softwares en su dispositivo, sólo conectarse a Internet (Johnson et al., 2010: 7 y 26).

La tabla 1 muestra los costes orientativos de software (abril 2011), que variarán en función de las características del producto contratado.

Tabla 1. Software para crear RA, proveedores y características

\begin{tabular}{|c|c|c|c|c|c|}
\hline Material & Plataforma & $\begin{array}{c}\text { Tipo de } \\
\text { seguimiento }\end{array}$ & $\begin{array}{c}\text { Libre / } \\
\text { Comercial }\end{array}$ & Precio & Contacto \\
\hline Build AR Free & $\mathrm{PC}$ & Marcadores & Libre & Gratuito & www.buildar.co.nz/ \\
\hline Build_AR Pro2.0 & $\mathrm{PC}-$ web & Marcas/Imagen & Comercial & $629 \$-435 €$ & www.buildar.co.nz/ \\
\hline Qualcomm SDK & $\begin{array}{l}\text { PC-móvil-web } \\
\text { smartphone } \\
\text { (Android/IPhone) }\end{array}$ & Marcas/Imagen & Libre & Gratuito & $\begin{array}{l}\text { https://ar.qualcomm.com/q } \\
\text { devnet }\end{array}$ \\
\hline Metaio- Design & $\mathrm{PC}$ & Marcas/Imagen & Comercial & $1.500 €$ & www.metaio.com \\
\hline Metaio-Viewer & Web & Marcas/imagen & Comercial & $3.000 €$ & www.metaio.com \\
\hline Metaio- Mobile SDK & Móvil & Marcas/imagen & Comercial & Consultar & www.metaio.com \\
\hline $\begin{array}{l}\text { D'Fusion SDK } \\
\text { (incluye D'Fusion Pro } \\
\text { D'Fusion@Home } \\
\text { D'Fusion@Home } \\
\text { Web D'Fusion Mobile) }\end{array}$ & PC-Web-Móvil & Marcas/imagen & Comercial & $\begin{array}{l}10 \text { licencias } \\
8.000 € \\
2 \text { licencias } \\
6.000 €\end{array}$ & www.t-immersion.com \\
\hline
\end{tabular}

\section{Resultados}

Las cabeceras revisadas, la demostración y el sondeo realizado revelan varios aspectos muy valorados de la RA. Tal y como se desprende de las columnas de los pros de la tabla 1, sobresalen la inmersión y la omnidireccionalidad, por generan la sensación de estar presente en el escenario recreado virtualmente (Botella et al., 2007: 33-36). También destacan el realismo, la capacidad expresiva y la interactividad que diferencian esta tecnología de otras utilizadas en periodismo impreso. Otras cualidades de la RA útiles en periodismo impreso son la creatividad, la originalidad y la no-linealidad. Son características positivas porque permiten que el receptor tenga una experiencia agradable a ver desplegarse imágenes a partir de las páginas de los periódicos. Son rasgos que cobran redoblado interés cuando los usuarios finales (los lectores) son jóvenes familiarizados con el uso cotidiano de las TIC y con las innovaciones permanentes.

Por su parte, el periodista comparte el disfrute de las ventajas anteriores, sumándosele el hecho de que, gracias a esta tecnología, dispone de un recurso narrativo que le facilita informar de tramas complejas.

Las empresas editoras también se ven afectadas al decidir incorporar esta tecnología. La innovación aporta diferenciación, posicionamiento y liderazgo respecto a los iguales. Como indica Nina Mikolaschek (2010: 9), la disminución de los ingresos en la industria de la prensa, por el paso de lo físico a lo virtual, reclama soluciones innovadoras, y la RA lo es con una inversión económica asumible. 
Frente a las ventajas, ciertos autores critican los efectos cognitivos, sensoriales e incluso emocionales que la RA causan en el usuario (Karppi, 2011: 3), relacionados con la hiperrealidad generada por unos medios cada vez más sensoriales. Son reparos patentes en la tabla 1 que permiten entender la reflexión a la que invita L. Pryor (2009: 4-7) sobre la aplicación de contenidos mixtos, a los que atribuye trascendencia por el tipo de edición y tratamiento periodísticos que implican. En esta línea, B. van Hövell previene sobre el uso negativo de esta tecnología bajo la forma de sesgo periodístico (Hövell, 2010).

A pesar de cierto rechazo inicial por determinados individuos, el sondeo realizado y la literatura especializada coinciden en que la RA es una tecnología de uso sencillo que permite prever una buena acogida entre periodistas y lectores. Además, el sondeo confirma lo observado en la bibliografía respecto a innovar para el fomento de la lectura de prensa entre los jóvenes. El deseado aumento de la lectura de prensa no radica sólo en la tecnología, pero influye, sobre todo si se aspira a ganar y fidelizar a jóvenes lectores (Hujanen y Pietikainen, 2004: 383-401).

\section{Conclusiones}

Según lo expuesto podemos concluir los puntos siguientes:

1. Por su coste, es factible vincular contenidos periodísticos aumentados mediante RA a piezas periodísticas concretas: una o varias entrevistas, reportajes o infografías por número editado.

2. Es una tecnología que involucra a varios participantes del proceso periodístico; un proceso que se vuelve más complejo al requerir la toma de decisiones, diseñar los contenidos (grabación de vídeo y audio, diseño de modelos 3D) y contar además de con el periodista, el reportero gráfico y el maquetador habituales, con un cámara de vídeo, un diseñador de modelos 3D y un informático. Sin embargo, una vez que se domina el procedimiento, la complejidad inicial pasa a ser una rutina y los tiempos de ejecución se acortan.

3. Para evitar que el sistema de visualización cause rechazo entre miembros de la redacción, es preciso invertir tiempo en su formación y asimilación.

4. Los lectores también deben reajustar las rutinas habituales frente al medio impreso, para acceder a los contenidos aumentados. El periódico podrá instruirlos en los requerimientos y pasos desde sus propias páginas

5. La RA es un recurso versátil para reconstruir y codificar la realidad informada, innova en la manera de elaborar piezas periodísticas y de informarse.

6. El aprovechamiento del potencial de la RA depende de la inversión y de la formación de los periodistas. Esto involucra el modelo de negocio y la gestión de la innovación en las empresas editoras.

7. Los contenidos aumentados no dependen de la temática ni de los géneros. Los tipos de usos son variados: desde los resultados del crucigrama o la viñeta hasta una entrevista o reportaje en profundidad. La cobertura de eventos in situ también constituye un uso rentable.

8. La posibilidad que da la RA de presentar hechos noticiosos mediante la convergencia tecnológica (papel, vídeo, audio, imagen 2D y 3D) lleva a algunos autores 
a hablar de información inteligente al ser real, objetiva, ampliada, combinada, complementada, añadir opciones de verificación de datos o de declaraciones, y al permitir infografías dinámicas, interactivas y en 3D.

9. La convergencia tecnológica exige adaptación a los profesionales de medios impresos para idear las piezas periodísticas en las que se articule el texto impreso con metainformación.

10. La creación de aplicaciones de RA es sencilla; los softwares se basan en la automatización del proceso y en la claridad de las interfaces de usuarios, por lo que con un mínimo esfuerzo en formación o autoformación es posible manejarlos.

11. El cuello de botella es la creación de contenidos digitales en 3D de manera rápida.

12. Los niños y jóvenes son públicos cuyo dominio de las TIC les predispone a ser lectores susceptibles de fidelizar, si se utiliza la RA como estrategia para ofrecer contenidos aumentados interesantes y divertidos de leer, ver, escuchar y experimentar, gracias al periódico impreso.

\section{Referencias bibliográficas}

ALCÁNTARA, Alfonso, ÁLVAREZ, Jacobo, ANTÚNEZ, José Luis y otros (2009): "Predicciones para los Social Media en 2010", en CORTÉS, Marc (coord.): Interactividad.org Reflexiones sobre Social Media y Marketing Electrónico, 23 de diciembre de 2009, 31 p.: http://es.scribd.com/doc/24431112/Social-Media -Predictions-2010\#archive

ARROYO-VÁZQUEZ, Natalia y GUALLAR, Javier (2010): “4th International LISEPI meeting: una mirada al futuro de la información". El profesional de la información, vol. 19, n 1, enero-febrero, pp. 101- 108.

AZUMA, Ronald (1997): "A survey of Augmented Reality”. Presence: Teleoperators and Virtual Environments, vol. 6, n 4, pp. 355-385.

AZUMA, Ronald; BAILLOT, Yohan; BEHRINGER, Reinhold; FEINER, Steven; JULIER, Simon; y MACINTYRE, Blair (2001): "Recent Advances in Augmented Reality". IEEE Computer Graphics and Applications, vol. 21, n ${ }^{\circ}$ 6, pp. 34-47.

BLOEM, Jaap y AART, Chris van (2010): "On Digital (Mobile) Humanism: helping understand it, engineer its future and ensure its social benefit", en Proceedings of the WebSci10: Extending the Frontiers of Society On-Line, 26-27 de abril, 2010, Raleigh (Carolina del Norte), pp. 1-7.

BOTELLA, Cristina, BAÑOS, Rosa, GARCÍA PALACIOS, Azucena, QUERO, Soledad, GUILLÉN, Verónica y MARCO, Heliodoro José (2007): "La utilización de las nuevas tecnologías de la información y la comunicación en psicología clínica". UOC Papers, Revista sobre la Sociedad del Conocimiento, $\mathrm{n}^{\circ}$ 004, pp. 32-41.

BRADSHAW, Paul (2010): “Augmenting reality through journalism”. Online Journalism Blog, 3 de febrero, 2010, 1 p. 
BUNZ, Mercedes (2010a): "Seven things you need to know about augmented reality", en Gardian.co.uk, 6 de enero de 2010: http://www.guardian.co.uk/media/pda /2010/jan/05/7-things-about-augmented-reality

BUNZ, Mercedes (2010b): "How journalists can use augmented reality", en Guardian.co.uk, 7 de enero de 2010: http://www.guardian.co.uk/media/pda /2010/jan/06/journalism-augmented-reality

CASALS CARRO, María Jesús (2006): "La enseñanza del periodismo y las nuevas tecnologías de la información y de la comunicación". Estudios sobre el Mensaje Periodístico, vol. 12, pp. 59-70. Madrid, Servicio de Publicaciones de la Universidad Complutense.

FEINER, Steven K. (2002): “Augmented Reality: A New Way of Seeing”. Scientific American Magazine, $\mathrm{n}^{\circ}$ de abril, pp.14-23.

FENN, Jackie (2010): "Emerging Technologies Hype Cycle 2010: What's Hot and What's Not", en Seminarios Gartner, Stamford, Connecticut: http://my.gartner.com $/$ portal $/$ server.pt?open $=512 \&$ objID $=202 \&$ mode $=2 \&$ PageID $=5553 \&$ resId $=1395613$

FUNDACIÓN TELEFÓNICA (2011): Informe 10: Realidad Aumentada: una nueva lente para ver el mundo. Madrid, Ariel, $90 \mathrm{pp}$.

HÖLLERER, Tobias, FEINER, Steven y PAVLIK, John (1999a): "Situated Documentaries: Embedding Multimedia Presentations in the Real World", en Proceedings of ISWC '99 (International Symposium on Wearable Computers), San Francisco, 18-19 de octubre, pp. 79-86: http://graphics.cs.columbia.edu/publications/iswc99.pdf

HÖLLERER, Tobias, FEINER, Steven y PAVLIK, John (1999b) "Situated Documentaries", en http://graphics.cs.columbia.edu/projects/mars/mjwSd.html

HÖVELL, Bertine van (2010): “Augmented Reality and Journalism”, en Aequilibria 'n stuff, 17 de mayo de 2010: http://www.atresica.nl/?p=5

HUJANEN, J. y PIETIKAINEN, S. (2004): "Interactive uses of journalism: crossing between technological potential and young people's news-using practices". New Media \& Society, vol. 6, n 3, pp. 383-401.

JOHNSON, L., SMITH, R., LEVINE, A. y HAYWOOD, K. (2010): 2010 Horizon Report: K-12 Edition. Austin (Texas), The New Media Consortium, 36 pp.

KARPPI, Tero (2011): "Reality Bites: Subjects of Augmented Reality Applications", en PURO, Jukka-Pekka y SIHVONEN, Jukka (eds.): Unfolding Media Studies Working Papers 2010, Turku (Finlandia), Media Studies, University of Turku, School of History, Culture and Arts Studies, pp. 89-102.

LAPOINTE, Pascal (2002): Utopie.net. La réalité Internet après le rêve. Sainte-Foy (Québec), Éditions MoltiMonde, 241 pp.

LINDSTEDT, Inger; LOWGREN, Jonas; REIMER, Bo; y TOPGAARD, Richard (2009): "Nonlinear news production and consumption: A collaborative approach". ACM Computer Entertainment, vol. 7, n 3, sep. 2009, pp. 1-21. 
MAES, Pattie y MISTRY, Pranav (2009): "Demo SixthSense", en TED Ideas Worth Spreading, febrero de 2009: http://www.ted.com/talks/lang/eng/pattie_maes _demos_the_sixth_sense.html

MADINAVEITIA, Eduardo (2011): "Visión de marketing y publicidad", en FUNDACIÓN TELEFÓNICA: Informe 10: Realidad Aumentada: una nueva lente para ver el mundo, Madrid, Ariel, pp. 79-81.

MENSING, Donica (2010): "Rethinking [again] the future of journalism education". Journalism Studies, vol. 11, no 4, pp. 511-523.

MIKOLASCHEK, Nina (2110): "Augmented reality and the strategic identity of the Apple: a culture and media scientific approach", en Seminário em Gestão de Imagem do Mestrado em Comunicação Estratégica, Lisboa, Faculdade de Ciências Sociais e Humanas, Universidade Nova de Lisboa, pp. 1-13.

MILGRAM, P. y KISHINO, F. (1994): "Taxonomy of mixed reality visual displays". IEICE Transactions on Information Systems, E77-D, n 12, pp. 1321-1329.

PAVLIK, John V. (2001): Journalism and new media. New York, Columbia University Press, 246 pp.

PAVLIK, John V. (2002): "New Technology and News Flows: Journalism and Crisis Coverage", en Panamerican Colloquium. Cultural Industries and Dialogue between Civilizations in the Americas, Montreal, 22-24 de abril de 2002, 12 pp.

PRYOR, Larry (2009): "IT and Democracy. An Analysis of the Power of Digital Images to Strengthen the Public Sphere and Decision-Making Process". Innovation Journalism, vol. 6, $\mathrm{n}^{\circ} 5$, pp. 1-15.

PURO, Jukka-Pekka (2011): "Turning Inside: Towards a Phenomenology of Biological Media”, en PURO, Jukka-Pekka y SIHVONEN, Jukka (eds.): Unfolding Media Studies Working Papers 2010, Turku (Finlandia), Media Studies, University of Turku, School of History, Culture and Arts Studies, pp. 123-135.

SALAVERRÍA, Ramón y GARCÍA AVILÉS, José Alberto (2008). "La convergencia tecnológica en los medios de comunicación: retos para el periodismo". Trípodos, $\mathrm{n}^{\mathrm{o}}$ 23, pp: 31-47.

THORNTON, Terri (2010): “Augmented Reality Invades Newsrooms, Kids' Shows, Ads", en GLASER, Mark (ed.): MediaShift, Arlington, Public Broadcasting Service (PBS), 2010: http://www.pbs.org/mediashift/2010/11/augmented-reality-invades-newsrooms-kids-shows-ads314.html\# 